\title{
THE TANDEM-X CHANGE DEM: STATUS OF THE CHANGE RAW DEMS PRODUCTION
}

\author{
Marie Lachaise, Markus Bachmann, Barbara Schweisshelm, Thomas Fritz \\ Remote Sensing Technology Institute, German Aerospace Center (DLR), \\ Münchner Str. 20, 82234 Oberpfaffenhofen, Germany \\ marie.lachaise@dlr.de
}

\begin{abstract}
In 2017, the TanDEM-X Mission decided to generate a second - more recent - global DEM. The acquisitions took place from 2017 till mid 2020 and represent a new global coverage of the whole Earth's landmass. This global dataset is well separated in time from the data used for the first global TanDEM-X DEM. Recent terrain height information can be delivered globally again with similar accuracy and consequently, terrain changes can be monitored. Currently, this data is being processed by the Integrated TanDEM-X Processor (ITP) into pre-calibrated single scenes. A reference DEM is a pre-requisite to enable a correct interferometric processing.
\end{abstract}

Index Terms - TanDEM-X Mission, Change DEM, terrain changes, ITP

\section{INTRODUCTION}

The TanDEM-X mission flies two similar satellites as a flexible, single-pass bistatic SAR interferometer since 2010. After having successfully generated the TanDEM-X global DEM in 2016, the mission decided to acquire an additional complete coverage of the Earth's landmass since the satellites have sufficient resources for several more years of operation [1]. Since the data used for the generation of the first global DEM, acquired between 2010 and 2015, is already several years old, many changes in the topography of the Earth occurred since then. The new goal is therefore to provide a second temporally independent dataset acquired within a well-defined time span from September 2017 to mid 2020. Its name "TanDEM-X Change DEM" emphasizes the new provided possibility to monitor topographic changes on a global scale by comparing it to the TanDEM-X DEM.

This paper recalls the acquisition concept as well as the special interferometric processing of this dataset. The main difference with respect to the original processing is that an edited reference DEM is used to enable reliable phase unwrapping. Finally, the current status of the production will be shown.

\section{ACQUISITIONS OVERVIEW}

Due to the shorter acquisition period and the now limited resources of the satellites, the acquisition plan for the Change DEM data had to be adapted. For example, the maximal duration of a data take must be shorter to avoid too fast degradation of the battery and there are fewer ground stations restraining dramatically the contact time per orbit. As a result, it was not possible to acquire two global coverages as for the first global TanDEM-X DEM. Yet, the experience and lessons learned from this first acquisition phase enable to improve the acquisition scenario in order to maximize the performance to generate a second global DEM of similarly high accuracy [2]. The Earth was divided into dedicated acquisition areas according to the dominant land classes, terrain types and seasonal changes as shown in Figure 1. Each region was assigned specific parameters constraining the acquisitions. Those are summarized in Table 1. Only glaciers (light blue), mountains and mountainous forests (red/pink areas) or mountainous deserts (orange) were acquired twice when possible.

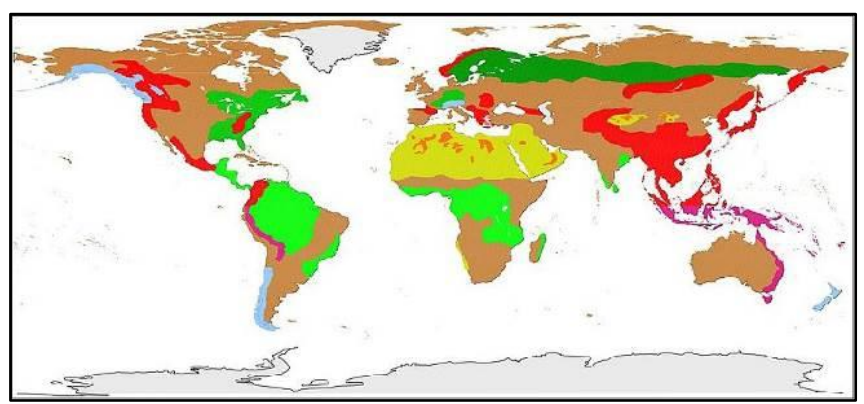

Figure 1 Areas covered during the TanDEM-X Change DEM acquisition phase (from 2017-09-21 until 2020-06-27)

During the acquisition of the Change DEM dataset, the system faced two further challenges. First, the number of conflicts with commercial and scientific customers increased. Second, in July 2019 the primary transmit chain on TDX-1 failed due to a malfunction of the first high power amplifier stage. The redundant chain was switched on and the operational TanDEM-X mission was re-activated after about 
two months of testing and calibration. Both challenges mentioned above lead to a prolongation of the acquisition phase from end of 2019 into the first half of 2020.

\begin{tabular}{|c|c|c|c|c|c|}
\hline Region & $\begin{array}{c}\text { Cov } \\
\text { era } \\
\text { ges }\end{array}$ & Season & $\begin{array}{c}\text { Height of } \\
\text { Ambiguity }\end{array}$ & $\begin{array}{c}\text { Incidence } \\
\text { Angle } \\
\text { Range }\end{array}$ & $\begin{array}{c}\text { Expected } \\
\text { Relative } \\
\text { Height Error }\end{array}$ \\
\hline $\begin{array}{c}\text { Mountains } \\
\text { with } \\
\text { forest }\end{array}$ & 2 & $\begin{array}{c}\text { Local } \\
\text { summer }\end{array}$ & $\begin{array}{c}55 \mathrm{~m}-75 \mathrm{~m}\left(1^{\text {st }}\right) \\
45 \mathrm{~m}-53 \mathrm{~m}\left(2^{\text {nd }}\right)\end{array}$ & $27-49 \mathrm{deg}$ & $2 \mathrm{~m}-4 \mathrm{~m}$ \\
\hline Glaciers & 2 & $\begin{array}{c}\text { Local } \\
\text { winter }\end{array}$ & $\begin{array}{c}55 \mathrm{~m}-75 \mathrm{~m}(1 \mathrm{st}) \\
45 \mathrm{~m}-53 \mathrm{~m}\left(2^{\text {nd }}\right)\end{array}$ & $29-47 \mathrm{deg}$ & $2 \mathrm{~m}-3 \mathrm{~m}$ \\
\hline $\begin{array}{c}\text { Tropical } \\
\text { forest }\end{array}$ & 1 & $\begin{array}{c}\text { Year } \\
\text { round }\end{array}$ & $50 \mathrm{~m}-60 \mathrm{~m}$ & $27-49 \mathrm{deg}$ & $2.5 \mathrm{~m}-4.5 \mathrm{~m}$ \\
$\begin{array}{c}\text { Temperate } \\
\text { and boreal } \\
\text { forest }\end{array}$ & 1 & $\begin{array}{c}\text { Local } \\
\text { summer }\end{array}$ & $50 \mathrm{~m}-55 \mathrm{~m}$ & $27-49 \mathrm{deg}$ & $2.5 \mathrm{~m}-4 \mathrm{~m}$ \\
\hline $\begin{array}{c}\text { Deserts } \\
\text { with } \\
\text { mountains }\end{array}$ & 2 & $\begin{array}{c}\text { Year } \\
\text { round }\end{array}$ & $55 \mathrm{~m}-75 \mathrm{~m}-55 \mathrm{~m}\left(2^{\mathrm{st})}\right)$ & $27-49 \mathrm{deg}$ & $3 \mathrm{~m}-7 \mathrm{~m}$ \\
\hline $\begin{array}{c}\text { Deserts } \\
\text { Den }\end{array}$ & 1 & $\begin{array}{c}\text { Year } \\
\text { round }\end{array}$ & $23 \mathrm{~m}-45 \mathrm{~m}$ & $14-38 \mathrm{deg}$ & $2.5 \mathrm{~m}-5 \mathrm{~m}$ \\
\hline $\begin{array}{c}\text { Rest of the } \\
\text { world }\end{array}$ & 1 & $\begin{array}{c}\text { Year } \\
\text { round }\end{array}$ & $35 \mathrm{~m}-45 \mathrm{~m}$ & $27-49 \mathrm{deg}$ & $1 \mathrm{~m}-2.5 \mathrm{~m}$ \\
\hline
\end{tabular}

Table 1 Acquisitions parameters and expected relative height error for the Change DEM acquisitions

In the meantime, the acquisition period is over and Figure 2 shows the acquisitions which successfully took place. Very few acquisitions could not happen and are currently being reacquired. Figure 3 exhibits the coherence of the data processed over Australia and New Zealand. The quality of the scenes is as expected.

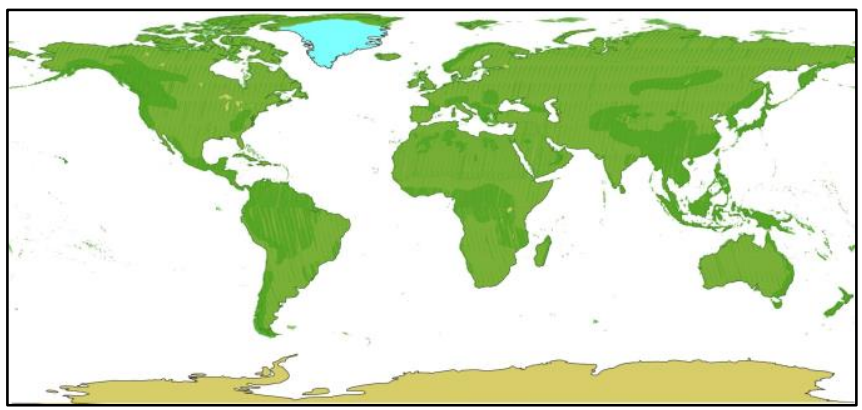

Figure 2 Successfully acquired data. Darker green indicates where two coverages could be acquired. Note that Greenland and outer regions of Antarctica were acquired in 2016/2017.

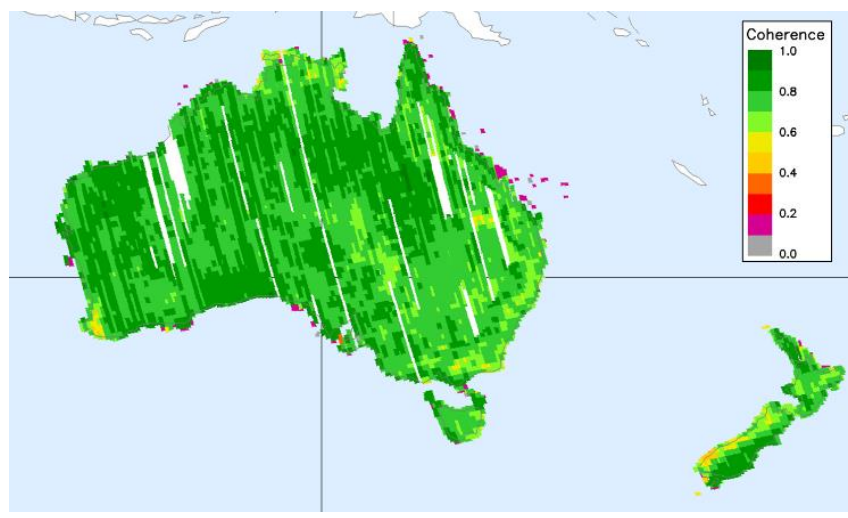

Figure 3 Quality of the processed acquisitions over Australia. The missing acquisitions are not yet processed or not processible in very few cases.

\section{INTERFEROMETRIC PROCESSING OF THE CHANGE DEM ACQUISITIONS}

\subsection{Overview}

With only one coverage, the interferometric processing had to be adapted. The dual-baseline framework is replaced by the so-called "delta-phase" approach [3] which uses an edited version of the global TanDEM-X DEM. Note that editing is required since it is an interferometric surface model which includes noise and artefacts from incoherent areas.

Figure 4 is the block diagram of the interferometric part of the ITP. Usage of the edited TanDEM-X DEM and the derived changes in the chain are marked in brown. More precisely, the phase simulated from the edited version of the global TanDEM-X DEM is now subtracted from the acquired interferometric phase in order to reduce the density and number of the interferometric fringes. Phase unwrapping is significantly facilitated and errors are nearly eliminated. The process also analyzes temporal changes [4] and uses stable areas for pre-calibration of the absolute height (absolute phase offset) of the Change Raw DEMs which is thus no longer based on the stereo-radargrammetric data exploitation. The pre-calibration of the individual (Raw) DEM scenes prior to geocoding reduces possible offsets and horizontal shifts in

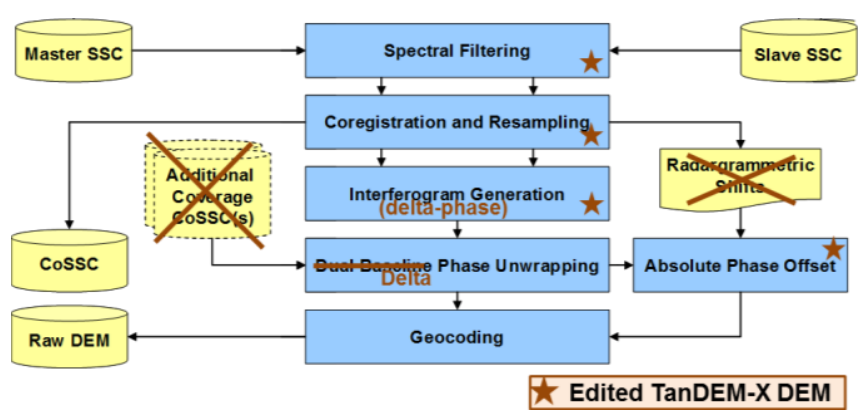

Figure 4 Update of the ITP interferometric part of the ITP to enable the processing of the new acquisitions. 
the data - facilitating greatly the final calibration and mosaicking. The usage of the edited DEM reduces the overall effort in the processing (no more re-processing due to the phase offset ambiguities) and calibration in order to mitigate the loss of freedom in the selection of suitable raw DEM data from the available coverages. Nevertheless, large scale errors in the edited DEM may not be fully recovered by the process and may affect the output DEM performance.

\subsection{Reference DEMs}

The global TanDEM-X DEM still contains some small gaps, and voids. Moreover, water bodies are characterized by noise as their height is exclusively derived from the interferometric SAR data. For phase unwrapping, these areas need to obtain valid elevation values. Two frameworks have been developed at DLR in order to edit TanDEM-X DEMs. Both are able to identify and flatten the water bodies, to interpolate void areas and perform edge-preserving smoothing:

- one framework is specific for Antarctic and Greenland. It is semi-automatic and focuses especially on the derivation of the land/ice-shelf water front. It is applied on the $12 \mathrm{~m}$ posting TanDEM-X DEM [5].

- the other one, for the rest of the world, derives and uses reference maps to identify water bodies and fill the voids. It is performed on the $30 \mathrm{~m}$ posting version of the global TanDEM-X DEM [6].

These two edited DEMs are complementary and are used as one reference DEM specifically for the processing for DLR and science users. All Change Raw DEMs generated with this reference DEM will be used to generate the (almost) global TanDEM-X Change DEM, the second global DEM of the TanDEM-X mission.

Nevertheless, these two editing processes are still on-going and the acquired data needs to be processed quickly so that the CoSSCs can be made available for the science users. Therefore, a separate production run with another reference DEM is taking place at the moment. The reference DEM is the WorldDEM30, a manually edited version of the global TanDEM-X DEM, provided by Airbus. It includes some special post processing especially for the needs of the interferometric processor and is reduced to $30 \mathrm{~m}$ posting [7].

\subsection{Change RawDEMs examples}

Figure 5 and 6 are two examples of a Change Raw DEM scene. They were generated with the WorldDEM30. Image a) is in both cases the Change RawDEM and image b) the geocoded phase differences w.r.t the reference DEM converted to height. These examples illustrate two different cases of height changes between the different TanDEM-X DEM acquisition periods and emphasize how useful this new global dataset is. Reference [4] provides more examples and also points out the limits of the terrain change detection within the operational interferometric processing.

\section{CHANGE RAW DEMS PRODUCTION STATUS}

The generation of the Change Raw DEMs with the WorldDEM30 started in November 2020. End of January 2021 , about $28 \%$ of the data is already processed and the corresponding CoSSCs are available for science users.

The generation of the CRawDEMs with the DLR in-house reference DEM is performed continent wise. For the moment, Australia and New Zealand have been processed and the final DEM is being prepared for these regions. Next regions to be processed within the next few months are Europe, South America, Greenland (order not fixed).

In the final paper, a more detailed status of the production with both reference DEMs will be given.

\section{CONCLUCION}

The TanDEM-X mission is now generating the Change RawDEMs with two different reference DEMs. The first global producion with the WorldDEM30 enables the provision of the CoSSCs to the science users within a shorter time frame. The second processing with the DLR reference DEM will enable the generation of an independent second global DEM to get more recent terrain height information.

\section{REFERENCES}

[1] S. Buckreuss, T. Fritz, M. Bachmann, M. Zink: "TerraSAR-X and TanDEM-X Mission Status," in European Conference on Synthetic Aperture Radar (EUSAR), 2018, pp. 1-4

[2] Rizzoli, P. et al.: "Generation and performance assessment of the global TanDEM-X digital elevation model". ISPRS Journal of Photogrammetry and Remote Sensing, 132, pp. 119-139, 2017

[3] Lachaise, M., Schweisshelm, B., Fritz, T.: "The new TanDEM$X$ Change DEM: specifications and interferometric processing". 2020 IEEE Latin American GRSS \& ISPRS Remote Sensing Conference (LAGIRS), Santiago, Chile, 2020, pp. 646-651

[4] Schweisshelm, B., Lachaise, M., Fritz, T.: "Change Detection within the processing of the TanDEM-X Change DEM". IGARSS 2021

[5] Huber, M-, Wessel, B., Wendleder, A. Hoffmann, J. and Roth, A.: A framework for an automated editing of TanDEM-X digital elevation models. Proceedings of IGARSS 2015, pp. 3826-2829, 2015

[6] Gonzalez C., Bachmann M., Bueso-Bello J.L:, Rizzoli P. and Zink M. : Automatic Editing of the TanDEM-X Global DEM, EUSAR 2020

[7] Airbus Defence and Space GmbH: "WorldDEM"TM: Technical Product Specification”, Version 2.5, April 2019 


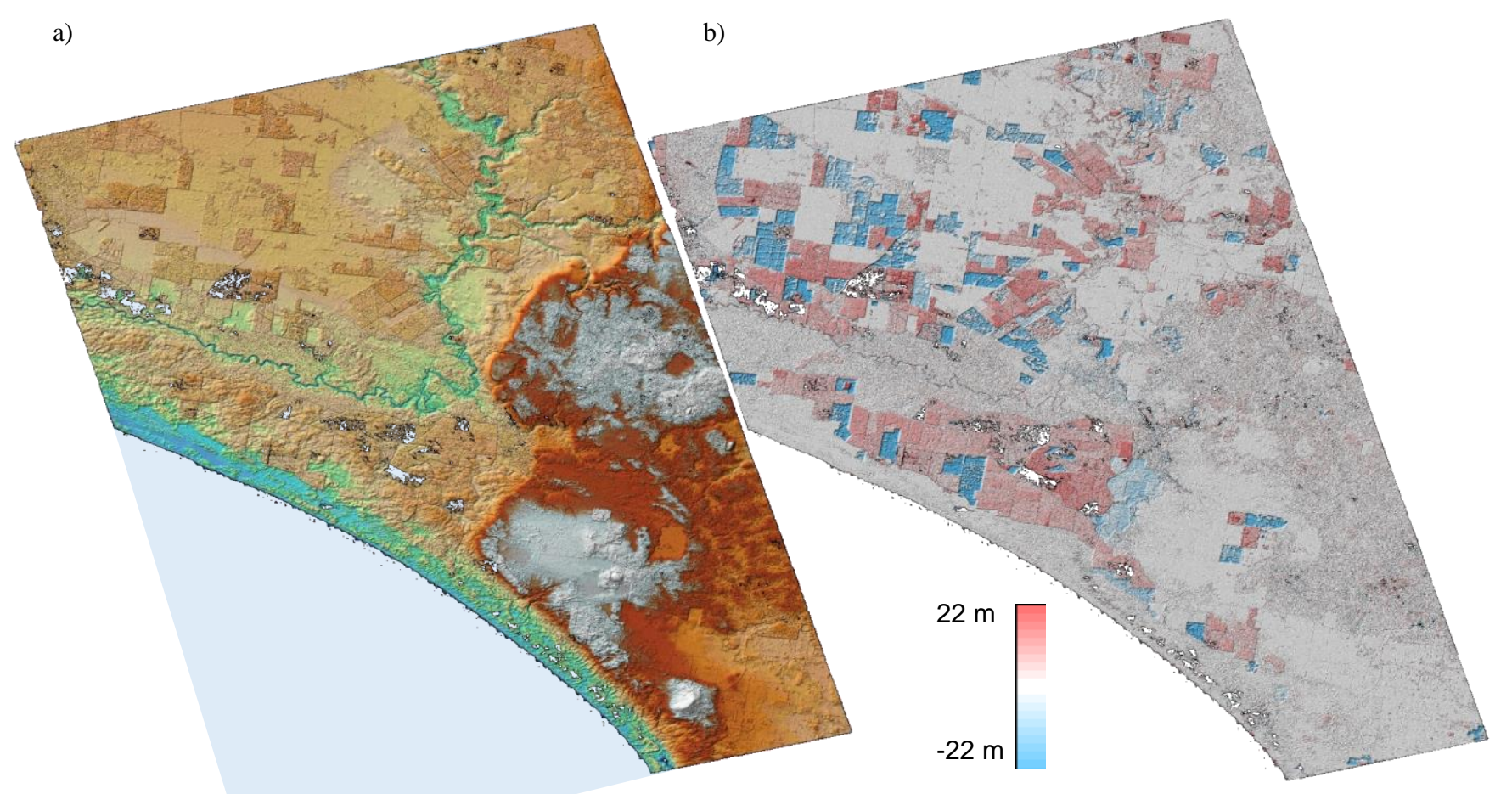

Figure 5 Scene in Australia near Mount Gambier. a) is the Change Raw DEM and b) is the geocoded phase difference transformed into height. This scene exhibits the changes due to agriculture and deforestation.
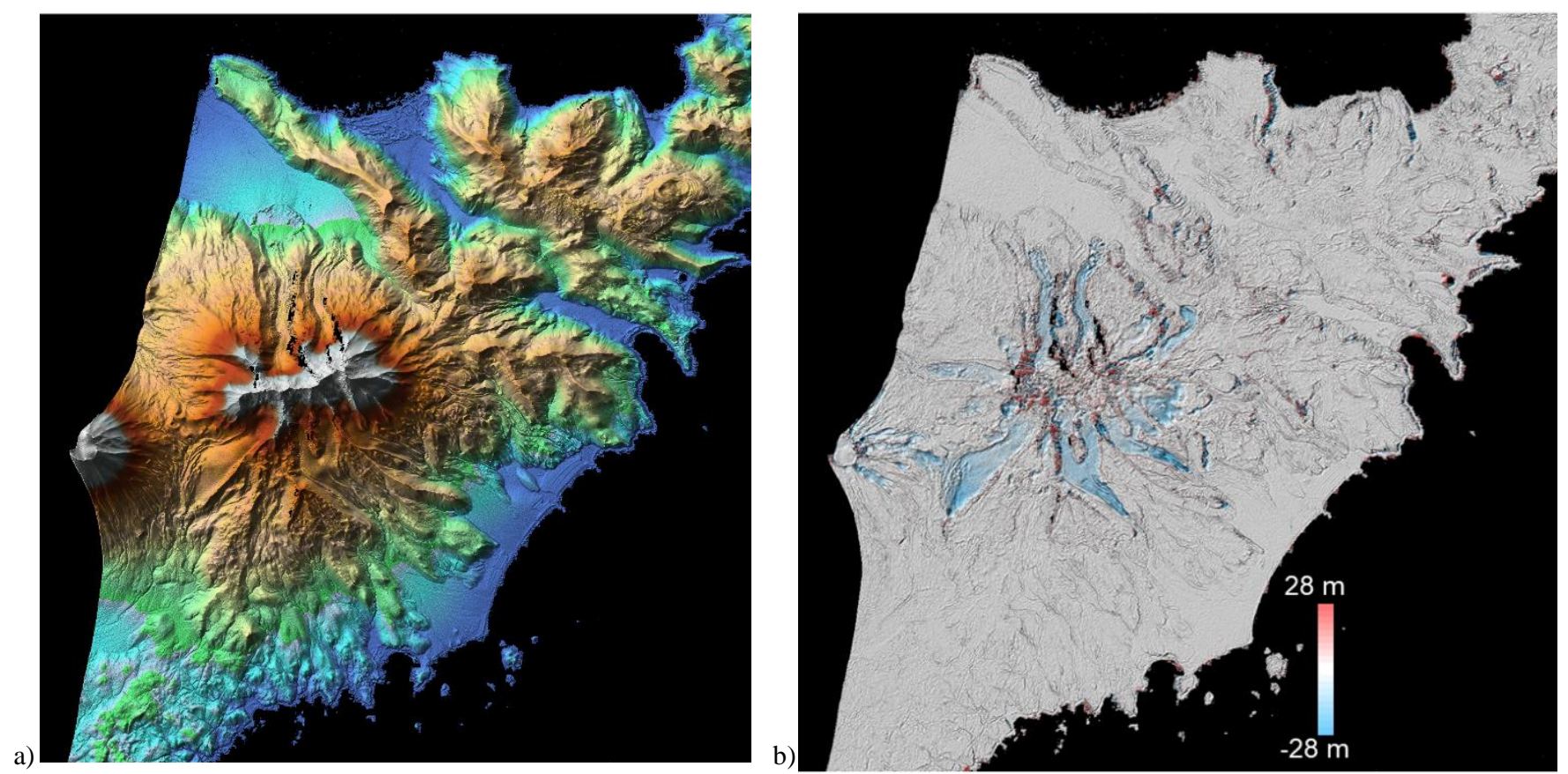

Figure 6 Scene in the USA around Mount Vsedvido. a) is the Change Raw DEM and b) is the geocoded phase difference transformed into height. This scene exhibits the changes due to changes in the glacial cover of these volcanoes. 